\title{
Issues in Software Maintenance
}

\author{
BENNET P. LIENTZ
}

Graduate School of Management, University of California, Los Angeles, California 90024

\begin{abstract}
Until a few years ago the area of software maintenance was largely ignored. Interest has increased recently for three reasons. First, the increased number of systems, combined with the increased volume of enhancement and maintenance, has restricted resources available for new development..Second, there has been a growing awareness that tools and aids that assist in developing systems may have little effect on operational systems. Third, the management of information systems has come under increasing scrutiny in terms of costs and resource utilization.

In this paper some of the major issues that surfaced during several extensive operational software studies are highlighted. These studies have raised significant questions about the roles of the users in operations and maintenance, the management of maintenance, and the kinds of tools and techniques that are needed for maintenance.
\end{abstract}

Categories and Subject Descriptors: D.2.7 [Software Engineering]: Distribution and Maintenance; K.6.3 [Management of Computing and Information Systems]:

Software Management-software maintenance

General Terms: Management

\section{INTRODUCTION}

During the past four years individual research efforts have been made to develop a better understanding of software maintenance and enhancement, and of operational software in general. Several resource- and research-related factors motivated this attention. First, software maintenance and operational support consume substantial hardware and software resources in the information systems environment. For example, some environments require multiple versions of data communications monitors and operating systems to keep their older application system running. This massive redundancy is necessary because the original application software was unable to $\mathrm{mi}$ grate to newer system software releases.

A second factor is the limited personnel availability. Turnover of system staff is a major concern for many organizations (over 30 percent per year in some organizations). In the area of operational software, turnover of maintenance personnel can cause reduced support of the application system and can even cause damage as untrained or unfamiliar staff attempt to implement a particular enhancement or maintenance fix.

A third factor is that much of the software engineering and computer science research has not yet touched on the problems associated with maintenance and operations. Research has produced many development tools and techniques, but they are not easily transferred to a maintenance environment involving large-scale operational applications that are over five years old. This research has not yet provided any alternative to rewriting the software using the new tools, often an expensive venture.

Permission to copy without fee all or part of this material is granted provided that the copies are not made or distributed for direct commercial advantage, the ACM copyright notice and the title of the publication and its date appear, and notice is given that copying is by permission of the Association for Computing Machinery. To copy otherwise, or to republish, requires a fee and/or specific permission.

(C) 1983 ACM 0360-0300/83/0900-271 $\$ 00.75$ 


\section{CONTENTS}

\section{INTRODUCTION}

1. RESEARCH METHODS

2. ISSUES IN APPLICATION SOFTWARE

MAINTENANCE

2.1 Conceptual Issues

2.2 Measurement Issues

2.3 Scale of Effort

2.4 Organizational Issues

2.5 Productivity Issues

3. PERCEIVED PROBLEM AREAS

4. CONCLUSIONS

ACKNOWLEDGMENT

REFERENCES

\section{RESEARCH METHODS}

The research program on maintenance began with a small survey of less than 100 systems (results reported in Lientz et al. [1978]). The survey was based on a 15-page questionnaire mailed to a variety of industrial, nonprofit, medical, financial, and other organizations in the western United States. A first result from the survey was that maintenance and enhancement were found to consume approximately half of the system and programming personnel hours. A second finding was that approximately 60 percent of the maintenance/enhancement effort was for perfective maintenance (e.g., system enhancements, improved documentation, and recoding for efficiency). This finding was somewhat unexpected since the literature had supported the belief that fixing problems and keeping systems operational were the major concerns. A third finding was that problems of a managerial nature dominated those of a technical nature in the view of the respondents.

Following the survey, we initiated an applied research program to determine what studies and analyses of maintenance had been carried out. With few exceptions, the meager literature cited results based on extremely small sample sizes. Some of the conclusions stated in the literature include the hypotheses that maintenance burdens continue to grow unabated, that staff morale and motivation are low, and that de- velopment tools could be used to reduce maintenance costs. In general, the hypotheses focused on the technical aspects of maintenance (see the work by Belady and Lehman [1976], Boehm [1975], Boehm et al. [1976], and Canning [1972] for some of the original findings).

The survey produced an increased interest in maintenance. Individuals contacted during the survey continued to pursue analysis, and several organizations adopted changes suggested as a result of the research. Because of the heightened interest, we were encouraged to do a larger sample size survey.

The large survey used a sample of 2000 management members of the Data Processing Management Association (DPMA). This organization was selected because it has the largest percentage of system personnel members working in industrial positions. Although the survey and its results are briefly described below, the survey methodology and results are contained in the book by Lientz and Swanson [1980], and summary results have been presented by Lientz and Swanson [1978, 1982].

The DPMA Foundation provided a randomly generated subset of the 10,000 members who classify their jobs as "management." The questionnaire was accompanied by an endorsement letter by the DPMA Foundation, as well as by return envelopes and follow-up postcards, enclosed to encourage response. We received 486 valid responses, a remarkably high number considering that the questionnaire was lengthy (over 17 pages) and conducted by mail. The data were entered into a computer and analyzed using the statistical routines in the statistics library package SPSS. Some of the major issues that surfaced are discussed in Section 2.

The 1977-1979 surveys were conducted with a base consisting mainly of business systems, as opposed to real-time, sensorbased systems. It was because of factory automation, improvements in commandand-control systems, and the increased number of on-line systems, that we felt the methodology should be applied to business systems.

In 1980 , a limited study of 18 weapon systems was undertaken for the Depart- 
ment of the Navy [Lientz and Wegner 1980]. Each of the software weapon systems is in operational use on a particular naval airplane, missile, or ship class. Unlike the group of business systems just surveyed, most of the naval systems were real time, fed by sensors and/or radar. The results of this study confirmed the findings of the larger previous study.

The questionnaires used in both the DPMA and the naval surveys were divided into two parts. The first part focused on the organization and on how maintenance was carried out in general. The second part focused on a particular application, selected by the respondent, which satisfied three criteria: (1) the system must have been in operation at least one year; (2) there needed to be significant maintenance work attached to the system; (3) the system had to be of major importance to the organization.

We used several methods to identify issues from the data. At the end of the questionnaire was a multiple item list of problem factors mentioned in the literature or inferred from previous versions of the questionnaire. This list of problems grew from 20 in the first version to over 30 in the most recent version. The 30 areas include management- and user-oriented issues, as well as technical ones.

To assess quality of response for quantitative answers, respondents were asked to indicate whether the response was reasonably accurate, based on good data; a rough estimate, based on numerical data; or best guess, not based on any data. Respondents were also asked about controls that were regularly employed and in place in the system. Included were such controls as logging requests, cost justification of change, trouble logging, formal audit, and charge back of costs (equipment and personnel). The later survey added specific controls for Defense Department standards.

Beyond these direct methods of identifying issues and how systems have been measured and controlled, we also obtained a number of indirect measures based on other data. For example, we found several longitudinal measures by collecting size data on current, one-year-previous, and two-year-previous systems from the number of people currently working on the sys- tem, the number who worked on the system in development and were still working with it in maintenance, and the percentage of effort in various maintenance and enhancement tasks.

\section{ISSUES AND PROBLEMS IN APPLICATION SOFTWARE MAINTENANCE}

From the three surveys, five areas of issues have emerged as dominant and comprehensive. We consider each of these in terms of both research and implementation concerns.

\subsection{Conceptual lssues}

In the surveys, we defined maintenance to include enhancements and operational support, as well as routine debugging and problem identification and resolution. More specifically, the questionnaires in the larger commercial survey and the naval survey included emergency fixes, routine debugging, accommodations of changes in file and data input, accommodation to hardware and software change, enhancements, documentation improvement, and recoding for efficiency. Enhancements were further divided into new reports, data addition, file reformatting, consolidation, file expansion, and condensation of data. In all three studies the research has shown that enhancements for users are the major activity (5070 percent of all maintenance and enhancement). Adaptation to new technology as a major activity surfaced only in the weapons systems survey. Emergency fixes and recoding for efficiency utilized relatively few resources (less than 20 percent) as did documentation (less than 5 percent).

Maintenance is related to the continued development of the application system. For many systems there appears to be no single linear life process, but rather a repeating life cycle. The present-day and one-yearprevious data indicated that once development was completed and the system stabilized in operational use, programmers began making enhancements individually or in groups of changes. The data indicated that while total maintenance in the organizations is at about the same level as development, maintenance on particular sys- 
tems first declined as the initial operational errors were fixed, and then increased as users requested enhancements. Belady also refers to this phenomenon in system software [Belady and Lehmann 1976]. However, the survey data were not sufficient to fully support the hypothesis that, as users request new enhancements, a new developmental cycle is begun.

The conceptual framework of maintenance needs a complete classification of the tasks and work done under the umbrella term maintenance. Swanson [1976] has begun this work. Although the concept of maintenance appears academic, there are substantial practical implications as well. For example, a classification method could be used to assist designers of project control systems. Even the rudimentary classification of perfective, adaptive, and corrective maintenance is already being used in a number of organizations, including system groups who want to charge their costs back to the user organization. The classification method has proved beneficial in estimating costs by task and by type of system.

\subsection{Measurement Issues}

To discuss maintenance, we need to know how to measure a system while it is undergoing maintenance. Surveyed systems of very similar sizes showed very different patterns of maintenance activity, with the surveys revealing the roles of the user and manager in maintenance activities and suggesting that measurement of the software be external, as well as internal, to the operation of the system.

To explore sources of potential change, we consider the environment of an application system. The environment consists of four factors, each of which can affect a system.

\subsubsection{User-External Environment}

The user-external environment includes legislation, competitive pressures, and social and cultural factors. It also includes the user's organization and its staffing. To explore the user-external environment, quantitative factors can be gathered. For instance, the requests for change can be classified by their ultimate source, the number of users actively working with the system can be counted, and user-developed systems can be assessed. Unfortunately, few, if any, measurements of this environment have been taken.

\subsubsection{Technological Change}

Technological change can affect applications by making possible new options. Distributed data processing or new, more intelligent terminals can split an application system across multiple computer systems. Other technology may make it possible to join or tie together separate applications.

\subsubsection{Managerial Factors}

Management frequently exerts pressure to control costs and modify schedules. This pressure can directly impact the quality and quantity of the maintenance effort. In particular, this pressure often causes the documentation of changes to be done insufficiently or not at all. Because managerial pressure focuses on the short term, it excludes attention to fundamental application system rework using new techniques. Who wants to expend the effort to rework something that works? This exclusion, in turn, prevents the use of productivity aids. Systems grow in size and complexity as enhancements accumulate, and, not unexpectedly, the surveys reveal that systems become more complex and difficult to maintain as they age. Contributing to the difficulty is the fact that the original staff, who know the application, leave the organization.

\subsubsection{Marketplace}

Just as technology produces new techniques and tools, the marketplace produces new products and services. The marketplace also creates competition for personnel, exerting pressure on the maintenance staff to leave their current jobs. Another effect is that new products and services often spur users to request more enhancements.

\subsection{Scale of Effort}

The traditional contention has been that the percentage of staff time spent in main- 
tenance is steadily increasing. The surveys do not bear that out. The data indicate that the percentage-about 50 percent of the total analysis and programming effortremains relatively stable in most organizations. Some organizations in the samples, though, report sharply rising percentages over a two-year period. The respondents in a substantial part of the surveys indicated that controls are exerted by management to reduce the percentage. Thus it appears that the scale of maintenance effort depends heavily on the organizational environment and the portfolio of application systems being developed and maintained at a given time.

\subsection{Organizational Issues}

Traditionally, general interest has centered on the organization of the maintenance function within a systems group. Common questions are whether maintenance should be separated or combined with new system development. But given the rising interest in and the impact of the user community on maintenance issues, analysts should consider more global issues: What is the role of the users in maintenance and enhancement? Should users be given report generators and other aids? Should users be responsible for production support? Today, the answer to these questions is "yes" in several minicomputer-based on-line systems.

The role of users is a major issue for systems groups in general. Nationally, we have a shortage of 20-30 percent in systems personnel. Users may play a role in filling the gap between supply and demand. This is happening today in many organizations and likely to continue as delays due to staff shortages lengthen. Because of this growing trend, the user's role in maintenance, enhancement, and operations needs to be more precisely assessed.

A separate, but related, organizational issue is that of system controls. Our surveys in the commercial sector reveal that many controls supported in education and theory are not used in practice, usually because of a trade-off between benefits of the controls and the cost of their implementation. Also, many organizations lack the technical im- plementation aids to make such controls feasible. Still to be determined is which groups of controls are appropriate to each category of application system.

\subsection{Productivity Issues}

A main research focus has been the productivity of programmers and, to a lesser extent, analysts in the system organization. Of the variety of techniques for increasing productivity, the surveys reveal only limited use. Furthermore, even in cases in which such techniques are employed, the results are not significantly different from those cases in which only traditional methods are used. It should be emphasized that the surveys provided no verification or control of the techniques among the respondents.

But is the productivity of programmers the major concern? The findings cited in the survey results, as well as those evident in measurement and organizational issues, point to the user and manager areas as more significant. There are far more users than there are developers or maintainers. Thus, if a productivity technique can be found to facilitate users' functions, its effect will be multiplied far more than a technique for programmers. It may be easier to increase the productivity of users with less complex tools, than to increase the productivity of programmers with more complex tasks.

A second area for which productivity tools have been developed is that of the analysis and design stages of system development and enhancement. These tools are designed to improve design correctness and completeness, since by explicitly specifying the requirements, the system will theoretically be easier to maintain and be more compatible with user needs. This view of the world was valid at a time when most systems were batch oriented and when users were not directly involved with systems. Today the situation has changed. Management pressures users to automate in order to control organization costs. Requirements no longer remain static. In many areas there are substantial yearly changes that necessitate major enhancements and retrofitting. 
1. Maintenance personnel turnover

2. Documentation quality

3. System hardware and software changes

4. Demand for enhancement and extensions

5. Skills of maintenance programmers

6. Quality of original programming

7. Number of maintenance programmers available

8. Competing demands for programmers time

9. Lack of user interest

10. System run failures

11. Lack of user understanding

12. Program storage requirements

13. Program processing time requirements

14. Maintenance programmer motivation

15. Forecasting maintenance programming requirements

16. Maintenance programmer productivity

17. System hardware and software reliability

18. Data integrity

19. Unrealistic user expectations

20. Adherence to programming standards

21. Management support

22. Adequacy of system design specifications

23. Budgetary pressures

24. Meeting scheduled commitments

25. Inadequate user training

26. Turnover in user organizations

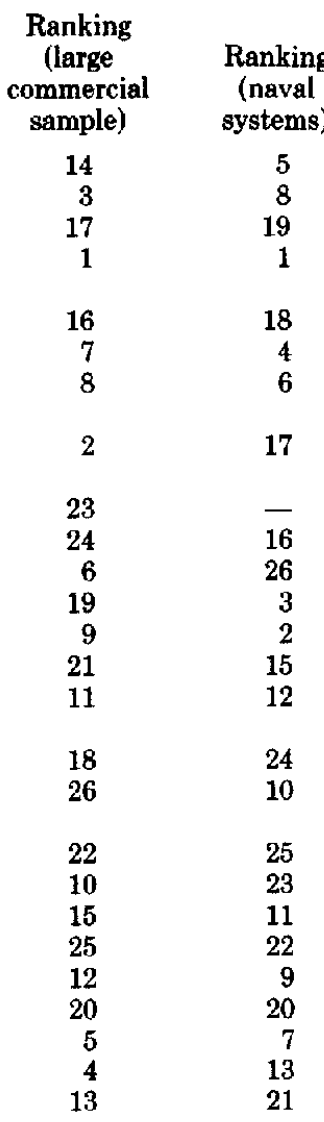

Figure 1. Potential problem factors in maintenance surveys.

\section{PERCEIVEd PROBLEM AREAS}

The major surveys provided respondents with 26 potential problem areas in maintenance. The respondents were asked to rank these on a scale of 1 (no problem) to 5 (major problem). A variety of problem areas, summarized in Figure 1, were suggested. The five problems seen as most severe were

- quality of application software documentation;

- user demand for enhancements and extensions;

- competing demands for maintenanceprogrammer personnel time;

- difficulty in meeting scheduled commitments;

- turnover in user organizations.

Of the most severe problems, three are concerned with users, two with the manage- ment function of apportioning resources, and one (documentation) with a technical issue. The predominance of nontechnical issues is striking.

Statistical analysis uncovered six overall groupings of problem areas listed in Table 1:

- user knowledge $(11,25)$;

- programmer effectiveness $(16,14,5)$;

- product quality $(22,6,2)$;

- programmer time availability (8);

- machine requirements $(12,13)$;

- system reliability $(17,18)$.

Additional statistical factor analysis was performed to determine which factors contributed to the variance. The ranking was the same as that given above, with user knowlege as the major component at 59.5 percent, followed by programmer effectiveness at 11.9 percent. User knowledge in- 
Table 1. Problem Factors and Their Components

User knowledge:

Lack of user understanding of application system

Inadequate training of user personnel

Programmer effectiveness:

Maintenance programming productivity

Motivation of maintenance programming personnel

Skills of maintenance programming personnel

Product quality:

Adequacy of application system design specifications

Quality of original programming of application system

Quality of application system documentation

Programmer time availability:

Competing demands for maintenance programming personnel time

Machine requirements:

Storage requirements of application system programs

Processing time requirements of application system programs

Systems reliability:

Systems hardware and software reliability

Data integrity in application system

cludes user training and user expectation of changes, as well as negative knowlege in the form of lack of user understanding. Programming effectiveness include skills and productivity of programmers. In the surveys, several potential problem areas widely mentioned in the literature failed to be significant. These areas included processing and storage requirements, data integrity, and hardware/software reliability. Migration of software to new generations of hardware was not viewed as significant by the survey. This is partially because the manufacturers often provide special software to aid such migration.

Of the top problems only one (documentation quality) emerges as more than a minor technically oriented prablem. The firstranked problem is user demand. Second ranked is competing demand for personnel time, an issue directly related to the role of users in maintenance and enhancement. If users were involved in more activities, their understanding of systems activities might improve, thus impacting demand. In many organizations a small number of people are significant resources for a range of systems and tasks, with intense competition for their time.

Of the top 16 items (those that ranked 2 on the scale of 1 to 5), six are management oriented, five are user oriented, and five are technical. Of the remaining ten items, all but two are technical.

Also in Figure 1 are the rankings for the military systems. Because these systems largely depend on older hardware with limited capabilities, respondents to this survey gave much significance to technical hardware and software issues. We hypothesize that survey data for many on-line systems at the hub of business organizations (e.g., demand deposit, on-line reservations) would probably be similar.

The impact of any personnel turnover was viewed by respondents as significant. The more experience and time staff had spent with the application system, the less the respondents perceived maintenance to be a problem. And, in fact, less maintenance effort was actually required for systems whose personnel had extensive time and experience with them.

In the context of problem areas, let us turn again to the productivity aids. Most of the aids that have been developed (e.g., structured programming, HIPO, structured walk through) have had limited impact. Tools such as test tools and automated documentation have been assessed [Lientz and Swanson 1980; Lientz and Wegner 1981], and the results indicate that no tool was used in over 30 percent of the applications. Furthermore, the use or nonuse of tools had little impact on the total amount of maintenance and enhancement required, except to slightly increase resources needed for the latter. The major problem with using tools is that it is too expensive to retrofit the system to take advantage of their capabilities. Further, many tools appear to wax and then wane in popularity. Yet application software maintenance must continue, sometimes long after the software tool or methodology technique has dropped from application and research favor.

\section{CONCLUSIONS}

Although much more research is needed in maintenance, the work thus far indicates that, in the future, consideration must be given to maintenance of user-intensive concerns, as well as of systems issues. Application system maintenance will continue to 
Table 2. Responsibility for Maintenance Areas

Sys- Oper-

\begin{tabular}{|c|c|c|c|}
\hline Area/activity & Users & $\begin{array}{l}\text { Sys- } \\
\text { tems }\end{array}$ & $\begin{array}{l}\text { Oper- } \\
\text { ations }\end{array}$ \\
\hline \multicolumn{4}{|l|}{ Production } \\
\hline Data entry & $x$ & & $x$ \\
\hline Inquiry & $\mathrm{x}$ & & \\
\hline Production initiation & & & \\
\hline Batch & $x$ & & $x$ \\
\hline Fixing problems & & $\mathrm{x}$ & \\
\hline \multicolumn{4}{|l|}{$\begin{array}{l}\text { Fixing prodiems } \\
\text { Enhancements }\end{array}$} \\
\hline Report generation & $x$ & & \\
\hline $\begin{array}{l}\text { Addition of new data ele- } \\
\text { ments }\end{array}$ & $\hat{x}$ & $\mathrm{x}$ & \\
\hline Addition of new functions & & $x$ & \\
\hline Modification of reports & $x$ & & \\
\hline Modification of system tables & & $\mathrm{x}$ & \\
\hline Requirements analysis & $x$ & & \\
\hline Design & $x$ & $\mathrm{x}$ & $x$ \\
\hline \multicolumn{4}{|l|}{ Maintenance } \\
\hline Recoding for efficiency & & $\mathbf{x}$ & \\
\hline Improving documentation & $x$ & $\ddot{x}$ & $x$ \\
\hline $\begin{array}{l}\text { Accommodating changes in } \\
\text { hardware/software }\end{array}$ & & $\ddot{x}$ & $\mathrm{x}$ \\
\hline $\begin{array}{l}\text { Accommodating changes in } \\
\text { files }\end{array}$ & & $x$ & \\
\hline $\begin{array}{l}\text { Accommodating changes in } \\
\text { input data }\end{array}$ & $x$ & & \\
\hline \multicolumn{4}{|l|}{ Management } \\
\hline $\begin{array}{l}\text { Monitoring of change re- } \\
\text { quests }\end{array}$ & $x$ & $x$ & \\
\hline Project control & & $\mathrm{x}$ & \\
\hline Cost accounting & $x$ & $\mathrm{x}$ & \\
\hline
\end{tabular}

be an area of concern but will become focused on substantial maintenance and enhancement, instead of on short-term activities such as fixes and patches. Table 2 indicates some of the activities of user, operations personnel, and systems staff responsibility.

Because we are now involving users on a larger scale, we have the opportunity to organize and control or coordinate user activities. Figure 1 shows the allocation of activities related to output reporting. The need will grow for user-operated and usermanaged tools, techniques, and aids. Satisfaction of these needs will probably take a more structured form than that of informal decision-support systems, since these tools will be exercised in conjunction with routine data processing and everyday business enterprises. Some of the issues that may arise in user maintenance involve documentation, interfaces to other systems, use of microcomputer software with base application system data, data quality, retention and recovery, user productivity, verification and testing, and technology transfer. To cope with these issues, a dual maintenance framework may emerge: one for base systems, emphasizing efficiency and control, and one for user-maintained functions and systems, supporting effectiveness and suitability to current organizational needs.

\section{ACKNOWLEDGMENT}

This work was partially supported by the Information Systems Program, Office of Naval Research under contract N00014-83-K-0257.

\section{REFERENCES}

BeLADY, L. A., AND LehMaN, M. M. 1976. A model of large program development. IBM Syst. J. 15, $3,225-252$.

Военм, В. W. 1975 . The high cost of software. In Practical Strategies for Developing Large Software Systems, E. Horowitz, Ed. Addison-Wesley, Reading, Mass.

BoEHM, B. W., Brown, J. R., AND Lipow, M. 1976. Quantitative evaluation of software quality. In Proceedings of the $2 d$ International Conference on Software Engineering (San Francisco, Calif., Oct. 13-15). IEEE Computer Society, Long Beach, Calif., pp. 592-605.

CAnning, R. G., Ed. 1972. That maintenance "iceberg." EDP Anal. 10 (Oct.).

Lientz, B. P., and Swanson, E. B. 1978. Discovering issues in software maintenance. Data Manage. 16 (Oct.), 15-18.

LiEnTz, B. P., AND Swanson, E. B. 1980. Software Maintenance Management-A Study of the Maintenance of Computer Application Software in 487 Data Processing Organizations. Addison-Wesley, Reading, Mass.

Lientz, B. P., And Swanson, E. B. 1981 . Problems in application software maintenance. Commun. ACM 24, 11 (Nov.), 763-769.

LIENTZ, B. P., AND WEgner, P. 1981. A survey of eighteen software command and control systems. Office of Naval Research Report.

Lientz, B. P., Swanson, E. B., and Tompkins, G. E. 1978. Characteristics of application software maintenance. Commun. ACM 21, 6 (June), 466471.

Swanson, E. B. 1976. The dimensions of maintenance. In Proceedings of the $2 d$ International Conference on Software Engineering (San Francisco, Calif., Oct. 13-15). IEEE Computer Society, Long Beach, Calif., pp. 492-497. 